\title{
José Juan Espinosa Zúñiga (2017), La Dirección Federal de Seguridad y sus actividades de espionaje en la Universidad Autónoma de Zacatecas, 1977, Zezen Baltza/Instituto Zacatecano de Cultura, Sindicato de Personal Académico de la Universidad Autónoma de Zacatecas, Secretaría de Cultura/Conacyt, Zacatecas
}

\author{
Mariana Terán Fuentes \\ Universidad Autónoma de Zacatecas \\ marianateranuaz@gmail.com
}

Como la institución de educación superior pública, la Universidad Autónoma de Zacatecas (UAZ) representa la oferta educativa más ambiciosa del estado de Zacatecas, tanto por sus indicadores en calidad y competitividad, como por la cobertura respecto de la población de dicha entidad. En 2018, la UAz cumple cincuenta años de su creación como universidad pública y autónoma, eslabón que habrá que reconocer dentro de la cadena que representa su largo pasado como Casa de Estudios de Jerez desde 1832, Instituto Literario de Zacatecas, Instituto Científico de Zacatecas y el logro de su autonomía en 1959. Una institución que ha permitido, a lo largo de casi dos siglos, formar tanto a la élite política durante el siglo XIX, como a una creciente población de diferentes sectores sociales a partir de la década de los años setenta.

A propósito de su quincuagésimo aniversario y de la publicación del libro La Dirección Federal de Seguridad y sus actividades de espionaje en la Universidad Autónoma de Zacatecas, 1977, de José Juan Espinosa Zúñiga, es pertinente reconocer algunas de las más importantes contribuciones historiográficas para el estudio de esta universidad dentro del campo de la historia de la educación.

Para entender la creación y desarrollo de lo que fuera la Casa de Estudios de Jerez y su transformación en Instituto Literario de Zacatecas, las contribuciones de Rosalina Ríos Zúñiga y de José Luis Acevedo Hurtado han abierto un camino que explica procesos de transición 
entre contenidos y métodos de enseñanza enmarcados en trayectorias en las que convergieron prácticas y contenidos secularizantes, con la permanencia de contenidos y prácticas heredados de la tradición monárquica católica. Por este tipo de investigaciones se han conocido los planes, programas, catedráticos, alumnos, rituales, así como los exámenes para optar por el grado de doctor o bachiller, dinámicas institucionales de procesos de enseñanza y aprendizaje, redes tejidas por los integrantes de la institución con las autoridades municipales y estatales de Zacatecas.

En este campo de estudios históricos sobre la institución, desde diferentes perspectivas e intereses historiográficos, se han desarrollado investigaciones con temas específicos, como la presencia de franceses en el Instituto Literario y Científico de Zacatecas, la revisión de su catálogo bibliográfico, la formación de la enseñanza de la ciencia durante el periodo porfiriano con las tesis doctorales de Xóchitl Marentes Esquivel, Olivia Hernández Aguilar y Froylán Díaz, en las que destaca la investigación documental y hemerográfica en distintos acervos estatales y nacionales. Su estudio ha enfatizado la importancia de esta institución en el desarrollo de nuevos saberes prácticos, humanísticos y científicos en la entidad, así como las relaciones políticas e interinstitucionales que se establecieron con los tres poderes de la entidad.

Si bien poco se sabe de la institución en algunas décadas del siglo XIX, a fines de esa centuria por los aportes de José Enciso Contreras, Cuauhtémoc Esparza Sánchez y Roberto Ramos Dávila se conoce su empuje en la ciencia, su participación en la vida pública de la entidad y sus logros en su avance académico, al abrir nuevas ofertas educativas para la juventud de los sectores de élite de la etapa porfiriana. Por sus contribuciones se conoce el importante papel que desempeñaron científicos locales de la talla de José Árbol y Bonilla en la rama del conocimiento astronómico; Ignacio Hierro, en la rama de la medicina y farmacéutica; Tomás Lorck y su vínculo con la cultura impresa y las asociaciones masónicas. Brillan por su ausencia los estudios sobre la institución durante la primera mitad del siglo xx, a no ser por menciones aisladas en investigaciones doctorales.

El logro de su autonomía ha sido más un interés para la opinión pública y los partidos políticos en la entidad, que un objeto de estudio dentro de la historia de la educación que explique, por ejemplo, sus relaciones entre el gobierno del estado, sus métodos de elección de autoridades, la vida cotidiana dentro del instituto, los vínculos diferenciados con la sociedad civil y política.

La única investigación consistente que se tomó en serio el problema de la autonomía fue Detrás del murmullo. Vida político-académica de la Universidad Autónoma de Zacatecas, 19591977; el volumen de Eduardo Remedi representa la investigación más completa sobre la institución, en su expresión como universidad pública estatal. Su autor entró a sus archivos, entrevistó a sus más representativos actores, desentrañó los años de conversión con la conquista 
de la autonomía, siendo Instituto de Ciencias y la transformación en universidad pública casi diez años después, en 1968. El tránsito tuvo fuerte impacto en la sociedad zacatecana por la posibilidad de incorporar en su oferta educativa a una numerosa población con diversos ascendentes sociales: hijos e hijas de campesinos, servidores públicos, obreros, artesanos y profesionistas de distintas licenciaturas.

Remedi Allione muestra el incremento de matrícula durante los años analizados, lo que supera esa idea enquistada de que gracias a la incorporación de ciertos líderes de izquierda esa institución tuvo que ensanchar sus horizontes. El crecimiento de la matrícula en las décadas de los setenta a los noventa también se debe a los presupuestos estatal y federal, a la participación de profesores en demanda de apertura de nuevas opciones educativas, a la inserción de la UAZ en el marco de la universidad pública en México.

¿La UAZ debe su existencia por su deuda con las organizaciones políticas y partidistas de izquierda durante la década de los setenta? Habrá que detenerse con más calma y escudriñar los archivos para valorar esta interpretación a la luz de sus cinco décadas. Podrá sugerirse la hipótesis de que la UAZ, durante aquella década, fue un actor político representativo que continuó con el proceso de invasión de tierras de campesinos del estado de Zacatecas, heredado del movimiento revolucionario agrarista, a partir de la Constitución de 1917. Eso puede ser materia de actuales debates, los cuales deberán enriquecer la discusión sobre el papel histórico de la universidad pública en el tema de justicia social en las entidades de la república. Los jóvenes profesores universitarios de entonces ahora recuerdan con nostalgia los años de movilización política universitaria y con agudas críticas objetan a las nuevas generaciones por su adormecimiento y falta de compromiso político. Esto también habrá que ponerlo en la mesa de discusión a sus cincuenta años de creación.

José Juan Espinosa escudriñó acuciosamente en los acervos del Archivo General de la Nación; encontró las carpetas sobre la participación de la Dirección Federal de Seguridad (DFS) relativas al movimiento universitario de Zacatecas de 1977, que hasta entonces se encontraban clasificadas dentro de un mar de documentos que consignan múltiples testimonios sobre movimientos políticos en el México contemporáneo. En 2002, a propósito de la Ley Federal de Transparencia y Acceso a la Información Pública Gubernamental, expedientes que hasta entonces se encontraban en estatus de "clasificados", fueron liberados, de ahí la oportunidad para que investigadores de distintas instituciones tuvieran oportunidad para su consulta y análisis. Es el caso de la contribución de Espinosa Zúñiga.

Este volumen hace un análisis de cada uno de los cincuenta informes recabados entre 1970 y 1977, la mayoría concentrados en este último año, cuando se dio el conflicto universitario en enero. El autor los vinculó con aquella tradición institucional de rendir informes para seguir la pista de investigaciones secretas a cargo de la Secretaría de Gobernación, con el objetivo de mantener en continua vigilancia los "focos rojos" que podrían haber representado 
las universidades públicas estatales, después de los movimientos estudiantiles de 1968 y 1971. El Estado mexicano no podía permitir su réplica en otras entidades como Jalisco y Zacatecas.

Espinosa Zúñiga ofrece un recorrido por la historia del espionaje en México, a partir del movimiento armado de 1910, el nacimiento de la policía política como organismo de vigilancia, control y defensa del Estado mexicano para la conservación de un determinado orden político y social. Entre los grupos históricamente vigilados, destacan los comunistas, agraristas, laboristas, sindicatos de trabajadores ferrocarrileros, de salud, del magisterio o electricistas, células partidistas de izquierda, universidades con sospechados (y confirmados) vínculos con dichas células.

La institucionalización de los servicios de espionaje presupuso perfiles para ocupar la dirección de este tipo de instituciones (en los setenta, sus directores fueron el capitán Luis de la Barreda Moreno y Javier García Paniagua), agentes de seguridad, estrategias de vigilancia, formas de captar la información y formas de transmitirla, como la elaboración de informes técnicos, en medio de prácticas informales (por ejemplo, extorsiones, chantajes, sobornos y redes de corrupción).

El autor considera algunos de los nudos que desataron una movilización que ha representado un parteaguas en la historia contemporánea de la educación pública en Zacatecas, a raíz de un problema que pudo haber tenido una resolución institucional, como lo fue el pase automático de estudiantes de preparatoria a la carrera de medicina, sin tener que realizar examen de admisión — petición sostenida desde 1971-, se nuclearon dos grupos políticos: Tendencia Democrática, que defendía el pase automático, integrado por líderes de izquierda con participación en la preparatoria y la Escuela de Economía, y Alianza Universitaria que rechazaba esta propuesta, integrado principalmente por profesores de la Escuela de Medicina. El conflicto rebasó la discusión y enfrentamiento verbal de posiciones al ocupar Alianza Universitaria las instalaciones de rectoría en enero de 1977. En los informes de los agentes de la DFS se califica a este grupo como de "derecha".

En el desfile de sucesos aparecieron presiones de preparatorianos, como la huelga de hambre, paro de labores de docentes en la Escuela de Medicina, toma de las instalaciones de rectoría, movilizaciones de padres de familia, mítines, viajes relámpago a la Ciudad de México por parte de autoridades universitarias. De especial relevancia resulta el informe del 11 de enero de 1977, en el que se reconocen organizaciones de izquierda con participación e influjo entre la comunidad universitaria, como el Frente Popular de Zacatecas, la Federación de Estudiantes Universitarios de Zacatecas, el Comité de Asambleas Conjuntas de Estudiantes, el Partido Mexicano de los Trabajadores, el Partido Comunista Mexicano, la Liga Comunista Internacional, la Central Independiente de Obreros, Agrícolas y Campesinos, la Liga Socialista Internacional o la Línea Troskista, y la focalización de profesores y estudiantes de la comunidad universitaria, con nombres y apellidos. El agente se guardó la información 
respecto de Alianza Universitaria porque no representaba en ese momento mayor preocupación por ser considerada "de derecha".

Las opiniones e interpretaciones alrededor de este conflicto en los años en que se le recuerda, a manera de conmemoración cívica universitaria, no han dejado de caer en un maniqueísmo en el que el grupo de Tendencia Democrática se lleva las palmas, dejando al grupo contrario adjetivos como conservador, reaccionario y, en el mejor de los casos, autoritario. Espinosa Zúñiga se distancia de este tipo de valoraciones y, en su lugar, presenta una cronología del conflicto universitario de 1977, a partir de los informes elaborados por los agentes secretos de la DFS.

A diferencia de otras situaciones de conflicto universitario, en Zacatecas el asunto no llegó a mayores; la participación de los agentes de la DFS no tuvo nada qué ver con otros casos de violencia física y violación de derechos humanos. Como señala Espinosa Zúñiga, la DFS "mostró su cara más amable, por llamarla de alguna forma, una que pocos conocieron, si la comparamos con su ominoso comportamiento en otros procesos y lugares".

El autor da cuenta, apoyado en los informes de la DFS, de la evolución del conflicto universitario: de las formas más radicales de resistencia, se pasó a hechos que ahora son considerados por los actores de entonces como verdaderas fórmulas democráticas, como la realización del referéndum, en medio del temor de comerciantes y locatarios, quienes se vieron en la necesidad de cerrar sus puertas en medio de las sirenas de patrullas de policía que no dejaban de rondar las principales calles del centro histórico de la ciudad. Parecía que el actor político de la capital zacatecana más importante era la universidad, no por sus hazañas científicas o tecnológicas, sino por su peso político para la gobernabilidad de la entidad.

En el referéndum se puso en juego quiénes estarían a cargo de la institución: si se aceptaba la renuncia del licenciado Jesús Manuel Díaz Casas (apoyado por Tendencia Democrática), o se continuaba con el rector interino, el doctor José de Jesús Martínez Estrada (apoyado por Alianza Universitaria). Una abrumadora mayoría (con 3,067 votos) optó por el rechazo de la renuncia, mientras que a favor de la segunda opción sólo se contabilizaron 81 votos. Pese a esta cantidad de votos emitidos, menos de la mitad de la comunidad universitaria participó en el acto. Con los resultados obtenidos no había duda de que el licenciado Díaz Casas regresaría a ocupar la rectoría, tal como ocurrrió el 5 de mayo de 1977.

Las reacciones del grupo perdedor fueron desde amenazar con dejar de pagar impuestos estatales y federales, hasta dejar de asistir a sus labores docentes, bajo un creciente ambiente estudiantil de exigencia para el regreso a las actividades académicas. Otro viaje a la Ciudad de México parecía imprescindible para la solución del conflicto. Fueron recibidos en la Secretaría de Gobernación por su titular, el licenciado Jesús Reyes Heroles. En la primera reunión sólo entraron los representantes de Alianza Universitaria para presionar y lograr su 
propósito: que fuese reconocido como rector el doctor Martínez Estrada, haciendo alusión al grupo contrario en calidad de comunista y desestabilizador del orden; en la segunda reunión, Reyes Heroles recibió a ambos grupos, en la que se llegó a un acuerdo para un pacto mínimo y volver a dar vida a la institución: al grupo de Tendencia Democrática se le reconoció que ocuparían los cargos de rectoría, secretaría general y tesorería, mientras que al grupo Alianza Universitaria se le otorgarían la contraloría y la secretaría general interna. ¿Una concesión de las autoridades federales con los "focos rojos" universitarios de izquierda en provincia para calmar las aguas? Espinosa Zúñiga es el único, hasta el momento, que ha dado cuenta de esta reunión entre el secretario de Gobernación y los grupos en conflicto, y la resolución que se tomó en esa reunión.

El autor concluye que el triunfo de los sectores de izquierda representados por Tendencia Democrática en el conflicto se debió a que los cohesionaban ciertos principios ideológicos, asociados con tradiciones y trayectorias de la izquierda mexicana de los años sesenta y setenta, a diferencia de sus contrarios que, pese a contar con estrategias de movilización, apoyo de comerciantes y padres de familia, vieron desmembrar su red por falta de una ideología que los cohesionara. Con el paso de los años, aquellos que fueron abiertos contrincantes, ahora se les ve juntos tomando un café en la nevería Acrópolis, en la legislatura estatal o en San Lázaro, como lo señala el autor.

Si bien algunas investigaciones, como las de Eduardo Remedi Allione y José Martín Ornelas expusieron noticias sueltas sobre los agentes de la Dirección Federal de Seguridad para realizar actividades de espionaje en esta institución educativa, la aportación de Espinosa Zúñiga radica en la recopilación y difusión de los informes de los enviados por la DFs, organizados cronológicamente como una fuente excepcional a tomar en cuenta para las investigaciones sobre la historia contemporánea de la educación superior pública en las entidades del país; fuente que nuevamente fue clasificada por el gobierno de Enrique Peña Nieto en 2015. 